\title{
Inflammation induced by very low-dose bisphenol-a can be prevented by probiotics
}

\author{
Merlin Nanayakkara ${ }^{1 \#}$, Ilaria Cimmino ${ }^{2 *}$, Claudio Cerchione ${ }^{3}$, Vittoria D'Esposito ${ }^{2}$, Francesco Oriente ${ }^{2}$, Riccardo Troncone ${ }^{1}$, Pietro \\ Formisano $^{2}$, Maria Vittoria Barone ${ }^{1 *}$ and Rossella Valentino ${ }^{2}$ \\ ${ }^{1}$ Department of Translational Medicine, Federico II University of Naples \& ELFID (European Laboratory for the Investigation of Food Induced Disease) \\ ${ }^{2}$ Department of Translational Medicine, Federico II University of Naples \& URT “Genomic of Diabetes" of the Institute of Experimental Endocrinology and \\ Oncology, National Council of Research (CNR), Naples, Italy \\ ${ }^{3}$ Hematology Unit, Istituto Scientifico Romagnolo per lo Studio e la Cura dei Tumori (IRST) IRCCS, 47014 Meldola, Italy \\ \#These authors contributed equally to this manuscript
}

\begin{abstract}
Bisphenol-A (BPA) is an endocrine disruptor found in the majority of plastic components with pro-inflammatory effects on adipose tissue, the immune system and the intestine, the first tissue exposed to the effects of BPA. Humans are chronically exposed to BPA through contaminated food and beverages. The aim of this study was to investigate the effect of a very low dose of BPA $(0.1 \mathrm{nM})$ on intestinal epithelial cells during differentiation, compare it with that of a low dose of BPA $(1 \mathrm{nM})$, and determine the role of probiotics in preventing BPA-induced alterations in intestinal permeability and inflammation.

Human colon adenocarcinoma-derived cells (Caco2 cells) were treated with $0.1 \mathrm{nM}$ and $1 \mathrm{nM}$ BPA in the presence of G-1 and G15, a specific GPR30 agonist and antagonist, respectively, and probiotics during differentiation, after which transepithelial electrical resistance (TEER) measurements, confocal fluorescence experiments, real-time RT-PCR and Western blot analysis were carried out.

Even at a dose of $0.1 \mathrm{nM}, \mathrm{BPA}$ significantly reduced TEER in differentiated Caco2 cells. The increased permeability of the enterocyte monolayer and a reduction in $\mathrm{Caco} 2$ cell thickness confirmed the effects of BPA. In addition, BPA induced GPR30 expression and ERK1/2 and NF- $\mathrm{kB}$ phosphorylation, especially in the early phase of $\mathrm{CaCo} 2$ cell differentiation. However, inhibition of GPR30 by G15 reduced the effect of BPA on ERK1/2 and NF- $\mathrm{BB}$ phosphorylation. Interestingly, the supernatant of cells grown with the probiotic LGG could prevent the decrease in TEER, alteration of tight junctions (TJs) and induction of $\mathrm{pNF}-\kappa \mathrm{B}$.
\end{abstract}

Very low-dose BPA $(0.1 \mathrm{nM})$ and low-dose BPA $(1 \mathrm{nM})$ induced intestinal inflammation and altered intestinal permeability through a mechanism involving GPR30. Treatment with the probiotic LGG reversed the effects of BPA.

\section{Introduction}

In Western countries, the prevalence of obesity, metabolic syndrome, diabetes, allergies, autoimmune diseases and inflammatory bowel disease (IBD) is rapidly increasing [1-6]. These conditions are most likely caused by the complex interaction between genetic susceptibility; immune deregulation driven by a response to commensal flora; and pharmacological, psychological and dietary factors $[7,8]$. In particular, the role of environmental chemical compounds in metabolic and inflammatory diseases in humans is supported by a large number of reports obtained from tissue culture, animal and human studies and epidemiological evidence [9-11]. BPA (Bisphenol A), an "obesogen" oestrogen-mimetic compound found in large quantities in plastics, has well-known effects on cell proliferation, inflammatory pathways, the immune system and the intestine [12-18]. Due to its distribution throughout the world, BPA plays an important role in the environmental influence on disease and human health [19]. Furthermore, BPA is released from food and drink containers made of tin and absorbed mainly by food and beverage ingestion. Hence, humans are chronically exposed to BPA, which first contacts the intestinal epithelium.

BPA can bind several oestrogen receptors, particularly the transmembrane non-classic oestrogen receptor GPR30, which mediates oestrogen-dependent rapid signalling events with non-genomic responses [20-22]. BPA can also be recovered from human fluids (0.1$10 \mathrm{nM})$. The concentration of BPA in human serum is approximately $0.1-1000 \mathrm{nM}[23,24]$. Several studies suggest that low concentrations of BPA can alter cells $[25,26]$. Earlier studies showed that BPA disrupts the intestinal barrier in rats and mice $[18,27,28]$.

Probiotics are defined by the World Health Organization as "live microorganisms that can provide benefits to human health when administered in adequate amounts, which confer a beneficial health effect on the host" (WHO/2001) [29]. Probiotics, used as a novel approach in the prevention and treatment of metabolic dysfunction, have gained significant attention in recent years. However, live probiotic bacteria need to colonize the gut to exert their functions, and colonization is not always efficient due to a variety of pathological or physiological conditions, especially when the subject is taking

${ }^{\star}$ Correspondence to: $\mathrm{M}$. Vittoria Barone, Department of Translational Medicine, Federico II University of Naples \& ELFID (European Laboratory for the Investigation of Food Induced Disease), Italy, E-mail: mv.barone@unina.it

Key words: bisphenol-A (BPA), endocrine-disrupting chemicals (EDC), enterocytes, inflammation, probiotic, post-biotic

Received: June 24, 2020; Accepted: July 13, 2020; Published: July 16, 2020 
gut bacteria-disrupting drugs. Post-biotics, resulting from probiotic fermentation in a matrix, do not need to colonize the gut and are considered an alternative approach to probiotics. Post-biotics have been used in the prevention of several disease conditions. Lactobacillus rhamnosus GG (LGG) is one the best characterized probiotic strains and has been widely used for the management of a variety of diseases [30]. Probiotics have been successfully used to prevent BPA activity in mice and to detoxify aqueous solutions [31,32]. Here we demonstrated that BPA induce inflammation and interfere with the intestinal permeability both a low doses and at very low doses, circa 1000 and 10000 times below the WHO accepted doses mainly in diffentiated Caco 2 cells. Moreover in this paper we showed that both in diffentiated and non -differentiated intestinal Caco2 cells markers of inflammation were increased by both low and very doses of BPA. Post-biotic from a very common probiotic such as LGG prevented both inflammation and alterations of the intestinal permeability induced by low and very low doses of BPA.

The active doses described in this manuscript are chronically present in our environment and regarded as unavoidable. Their effect on inflammation and intestinal permeability could create a predisposing environment for several diseases including metabolic diseases and intestinal inflammatory diseases (IBD). Post-biotics preventing these effects could have an important impact on both health and in disease.

In this study, we investigated the role of low $(1 \mathrm{nM})$ and very low $(0.1 \mathrm{nM})$ doses of BPA on intestinal epithelial cells and the effects of the post-biotic LGG using a human colon adenocarcinoma-derived cell line (Caco2) during differentiation.

\section{Materials and methods}

\section{Cell culture, materials, and reagents}

Human colon adenocarcinoma-derived cells (Caco2 cells), [33] which are colon carcinoma cells that can be differentiated into epithelial-like cells, were grown in monolayers and treated with different concentrations of BPA $(0.1 \mathrm{nM}$ and $1 \mathrm{nM})$ over their differentiation (20 days). Caco2 cells obtained from Interlab Cell Line Collection (Centro di Biotecnologie Avanzate, Genoa, Italy) were grown in DMEM supplemented with $10 \%$ foetal calf serum, 100 units penicillin-streptomycin/mL, and $1 \mathrm{mmol} / \mathrm{L}$ glutamine (All these products are Gibco Invitrogen, Milan, Italy). Cells were maintained in a humidified atmosphere $(95 \%)$ of air and $5 \% \mathrm{CO}^{2}$ at $37^{\circ} \mathrm{C}$. Singlecell suspensions were obtained from 70 to $80 \%$ confluent cultures and then seeded at $10^{5}$ cells $/ \mathrm{cm}^{2}$ onto 13 - or $25-\mathrm{mm}$ glass coverslips with detachable polycarbonate microporous cell culture inserts (Transwell, 24-mm diameter, 0.4-mm pore size; Corning, NY, USA).

Bisphenol-A (BPA) was supplied by Sigma-Aldrich Chemical Co., (Milan, Italy). G-1, a GPR30 agonist (100 nM), and G15, a GPR30 antagonist $(1 \mu \mathrm{M})$, were purchased from Azano Pharmaceuticals Inc. (Albuquerque, NM). All other chemicals were from Sigma Chemical Co. (St. Louis, MO, USA).

\section{Transepithelial electrical resistance experiments}

Transepithelial electrical resistance (TEER), the measurement of electrical resistance across a cellular monolayer, is a very sensitive and reliable method to confirm the integrity and permeability of the monolayer. TEER over a 48 -h period was measured as previously described [34]. Briefly, after we removed the Transwell apparatus from the incubator, we allowed a 10 -min incubation time under a sterile hood to allow acclimatization of the sample. Then, we measured the
TEER in each Transwell with a $1.0-\mathrm{cm}^{2}$ planar electrode connected to a voltmeter (Millipore, Billerica, MA).

Because vectorial electrolyte transport requires cells to grow in a polarized fashion with structured intercellular TJs, the Caco 2 cells needed to be cultured for at least 20 days before experiments ( $\sim 11-13$ days after confluence). TEER in the cell monolayer was measured every $48 \mathrm{~h}$ from 2 to 20 days after seeding and treatment with BPA at $0.1 \mathrm{nM}$ and $1 \mathrm{nM}$ to evaluate permeability during differentiation.

\section{Confocal fluorescence microscope: Occludin staining}

Caco2 cells seeded on glass coverslips were treated every $48 \mathrm{~h}$ with $0.1 \mathrm{nM}$ or $1 \mathrm{nM}$ BPA for 20 days during differentiation. The cells were fixed in $3 \%$ paraformaldehyde for $10 \mathrm{~min}$, permeabilized with $0.2 \%$ Triton X-100 for $10 \mathrm{~min}$, and blocked in 1\% FBS-PBS for $30 \mathrm{~min}$ at room temperature. Staining with polyclonal anti-rabbit occludin antibody (1:100; Santa Cruz, DBA Milan, Italy) was performed for $1 \mathrm{~h}$ in a dark humid chamber. The cells were then incubated with Alexa-488 conjugated (Invitrogen, Milan, Italy) anti-rabbit secondary antibody for $45 \mathrm{~min}$ at room temperature. The cells were mounted and then examined with a confocal fluorescence microscope (LSM 510; Zeiss, Leipzig, Germany) [35]. Colocalization analysis was performed with AIS Zeiss software as previously described [36]. Micrographs are shown in the figures at the same magnification $(63 \times$ objective) unless stated differently in the figure legend.

Then, we obtained scanned images of samples in three dimensions along the optical axis (identified as the z-axis) without the need for mathematical operations. This confocal fluorescence microscopy technique allowed us to directly study the entire intestinal cell volume in living cells in a 3-D arrangement using actin as the fluorescent dye.

\section{Western blot analysis}

Caco2 cells that were seeded and incubated for 3-20 days were treated with $0.1 \mathrm{nM}$ and $1 \mathrm{nM} \mathrm{BPA}$ and the GPR30 agonist or antagonist G-1 or G15, respectively, for 30 minutes. The cells were washed twice and resuspended in lysis buffer $(50 \mathrm{mM}$ Tris- $\mathrm{HCl}(\mathrm{pH}$ 7.4), 1 mM EDTA, 1 mM EGTA, $5 \mathrm{mM} \mathrm{MgCl} 2,150 \mathrm{mM} \mathrm{NaCl}, 1 \%$ Triton, $1 \mathrm{mM}$ PMSF, $1 \mathrm{mM}$ VO4, 100× Aprotinin, and 50× LAP, all of which were purchased from Sigma, Milan, Italy, except for LAP, which was obtained from Roche, Milan, Italy). The cell lysates were analysed using SDS-PAGE with a standard running buffer (25 mM Tris, $192 \mathrm{mM}$ glycine, and $0.1 \%$ SDS) and transferred onto nitrocellulose membranes (Whatman Gmbh, Dassel, Germany) using transfer buffer $(25 \mathrm{mM}$ Tris, $192 \mathrm{mM}$ glycine, $0.1 \%$ SDS, and $20 \%$ methanol, all of which were purchased from Sigma-Aldrich, Milan, Italy). The membranes were blocked with $5 \%$ nonfat dry milk and probed with mouse antipY-ERK1/2 and rabbit anti-ERK1/2 (Santa Cruz, Milan, Italy), rabbit anti-pNF- $\kappa B$ (Cell Signaling, Euroclone, Milan, Italy) and mouse antitubulin (Sigma-Aldrich, Milan, Italy). The bands were visualized using ECL (GE Healthcare, Amersham, Buckinghamshire, UK) with exposure times of $2-10 \mathrm{~min}$. The band intensity was evaluated by integrating all the pixels of a band after subtraction of the background to calculate the average of the pixels surrounding the band $[35,36]$.

\section{Real-time RT-PCR analysis}

Total cellular RNA was isolated from Caco2 cells by using the RNeasy Kit (Qiagen, Valencia, CA, USA) according to the manufacturer's instructions and as previously described [37,38]. Reactions were performed in triplicate, and Peptidylprolyl isomerase A (PPIA) was used as an internal standard. Primer sequences used for real-time RTPCR analysis are described in Table 1. 
Table 1. Primer sequences used for real-time RT-PCR analysis (List of abbreviations. GPR30: G protein-coupled oestrogen receptor-30, IL-7: interleukin-7, MCP-1: Monocyte chemo-attractant protein-1, PPIA: Peptidylprolyl isomerase A)

\begin{tabular}{|c|c|}
\hline GENE & SEQUENCES \\
\hline \multirow{2}{*}{ GPR30 } & $\begin{array}{c}\text { Forward: 5'- CTTCATCGTGCCCTTCGCC -3' } \\
\text { Reverse: 5'- GAGAAGGCGGCGAGGTTGA-3' }\end{array}$ \\
\hline \multirow{2}{*}{ IL-7 } & Forward: 5'- ACTTCCTCCCCTGATCCTTG-3' \\
& Reverse: 5'-GCTGTCCAATAATTGATCGATGC-3' \\
\hline \multirow{2}{*}{ MCP-1 } & Forward: 5'- CTCTGCCGCCCTTCTGTG -3' \\
& Reverse: 5'- GGGACACTTGCTGCTGGT -3' \\
\hline \multirow{2}{*}{ PPIA } & Forward: 5'- TACGGGTCCTGGCATCTTGT-3' \\
& Reverse: 5'- GGTGATCTTCTTGCTGGTCT-3' \\
\hline
\end{tabular}

\section{Cytokine, chemokine and growth factor assays}

A panel of 27 different cytokines, chemokines and growth factors produced by differentiated Caco2 cells was determined in the culture supernatants using the Bio-Plex multiplex human cytokine and growth factor assay kit (Bio-Rad, Hercules, CA, USA) according to the manufacturer's instructions as previously described [39]. In particular, $\mathrm{Caco} 2$ conditioned media were checked during differentiation, specifically at the beginning (day 3 ) and end (day 20) of differentiation.

\section{Protocol for the preparation of LGG supernatant}

Lactobacillus rhamnosus GG (LGG) $\left(5 \times 10^{9} \mathrm{CFU}\right)$, purchased from Dicofarm (ATCC53103) was grown in $50 \mathrm{ml}$ of DMEM supplemented with FBS and glutamine without antibiotics. The culture was incubated overnight at $37^{\circ} \mathrm{C}$ in an oscillator (Thermo, Euroclone, Milan, Italy; 160 oscillations per minute). The bacterial concentration was measured by spectrophotometric reading (Beckman DU-7, Chaska, MN) at a wavelength of $600 \mathrm{~nm}$; reading of the optical density (OD) allowed calculation of the bacterial concentration with the following equation: OD $2=1.5 \times 10^{9}$ colony-forming units $(\mathrm{CFU}) / \mathrm{ml}$. The bacterial culture was centrifuged at $3000 \mathrm{rpm}$ for $10 \mathrm{~min}$ at room temperature. The supernatant was recovered and filtered with 0.22-micron filters [40-42].

\section{Statistical analysis}

GraphPad Prism 5.lnk software (GraphPad Software, San Diego, CA, USA) was used for statistical analyses and to construct graphical representations. Statistical analyses of differences were performed using ANOVA with Bonferroni correction. A p value $<0.05$ indicated statistical significance. The numbers of replicates used for statistical analyses are shown in the figures.

\section{Results}

\section{Effects of bisphenol-A (BPA) on permeability, barrier function and thickness}

Transepithelial electrical resistance (TEER) of Caco2 cells, a colon carcinoma cell line that can be differentiated into intestinal epitheliallike cells, is a good marker of barrier integrity. Caco2 cells were grown in monolayers and treated every $48 \mathrm{~h}$ with $0.1 \mathrm{nM}$ or $1 \mathrm{nM}$ BPA during differentiation (20 days). A significant decrease in TEER was observed after 17 and 20 days of treatment with BPA when compared to the TEER in control cells treated with BPA at both concentrations $(\mathrm{p}<0.01$, $\mathrm{p}<0.001$ ) (Figures $1 \mathrm{~A}$ and $1 \mathrm{~B}$ ). Next, the integrity of tight junctions (TJs) was evaluated at the same time point at which the TEER decreased by testing the levels of occludin, a structural TJ protein. After 17 days of culture, the expression of occludin showed a significant decrease $(\mathrm{p}<0.05)$ in the presence of BPA at both concentrations, as shown by Western blot analyses (Figures 1C and 1D) and immunofluorescence (Figure 1E).
Confocal microscopy allows scanning of thin planes in a sample along the optical $z$-axis by controlled micrometre increments. BPA reduced the cell thickness, as measured by the optical $z$-axis, from 40 micrometres in the control samples to 12 micrometres in the samples treated with BPA at both $0.1 \mathrm{nM}$ and $1 \mathrm{nM}$ (Figure $1 \mathrm{~F}$ ).

\section{Effects of BPA on intracellular pathways and inflammation}

BPA is defined as a "weak oestrogen". Several studies support that BPA-dependent oestrogenic activity is mediated by G-protein-coupled receptor 30 (GRP30) activation, which results in ERK/MAPK and AKT phosphorylation [43]. We investigated the ability of BPA to induce ERK1/2 phosphorylation in Caco2 cells on both the third and twentieth days of differentiation. Incubation of the cells for 30 minutes with 0.1 $\mathrm{nM}$ and $1 \mathrm{nM}$ BPA significantly increased ERK1/2 phosphorylation at both times $(\mathrm{p}<0.001)$ (Figures $2 \mathrm{~A}$ and $2 \mathrm{~B})$.

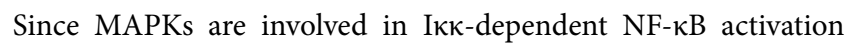
[44], we evaluated the levels of phosphorylated NF- $\mathrm{B}$ (p65) on the third and twentieth days of differentiation in the presence of $0.1 \mathrm{nM}$ and $1 \mathrm{nM}$ BPA for 30 minutes. BPA at both concentrations stimulated the phosphorylation of pNF- $\mathrm{kB}$ in a statistically significant way at the early stage of differentiation, suggesting that NF- $\kappa \mathrm{B}$ is involved in BPAmediated inflammatory reactions in both immature and differentiated Caco2 cells (Figures 2C and 2D).

Next, we measured the expression of 27 different cytokines, chemokines and growth factors in the supernatants of differentiated Caco 2 cells. Our results indicated a modest increase in interleukin-7 (IL7) and monocyte chemo-attractant protein-1 (MCP-1/CCL2) secretion in the cell culture medium upon $0.1 \mathrm{nM}$ and $1 \mathrm{nM}$ BPA treatment ( $\mathrm{p}<0.05$ and $\mathrm{p}<0.01$, respectively) (Table 2 ). In addition, in $1 \mathrm{nM} \mathrm{BPA-}$ treated $\mathrm{Caco} 2$ cells, we confirmed a modest increase in IL-7 and MCP-1 mRNA levels, particularly in the early phase of differentiation $(\mathrm{p}<0.01$ and $\mathrm{p}<0.001$, respectively) (Figures $2 \mathrm{E}$ and $2 \mathrm{~F}$ ). All these data suggest that low and very low concentrations of BPA increase inflammatory markers.

\section{Effects of very low-dose bisphenol-A (BPA) on GPR30 expression and function}

Caco2 cells expressed ERß at very low levels, but ERa was not detectable (data not shown). GPR30 mRNA levels measured by RT-PCR were significantly increased upon $0.1 \mathrm{nM}$ and $1 \mathrm{nM}$ BPA incubation $(\mathrm{p}<0.01, \mathrm{p}<0.001)$ (Figure 3A). To determine whether the effects of BPA are mediated by activation of the GPR30 receptor, we used a GPR30selective agonist (G-1) and a specific GPR30 antagonist (G15). The treatment of Caco 2 cells with $0.1 \mathrm{nM}$ and $1 \mathrm{nM}$ BPA induced ERK1/2 and p65 activation at both stages of differentiation ( 3 and 20 days), similar to that induced after G-1 stimulation. In contrast, G15 reversed the effect of BPA during differentiation (Figures 3B-3L).

By confocal microscopy, we observed that both BPA and G1 decreased occludin levels, while G15 reversed this effect, suggesting that the modifications of occludin levels induced by BPA can be mediated by GPR30 (Figure 3B).

\section{LGG supernatant treatment improved the intestinal barrier and prevented BPA-induced inflammation}

We next evaluated whether post-biotic treatment could prevent the effects of BPA on the intestinal barrier and inflammation. To this end, we added LGG supernatant (LGG) to $\mathrm{CaCo} 2$ cells on the seventeenth day of differentiation and incubated them for 24 hours. Under these 


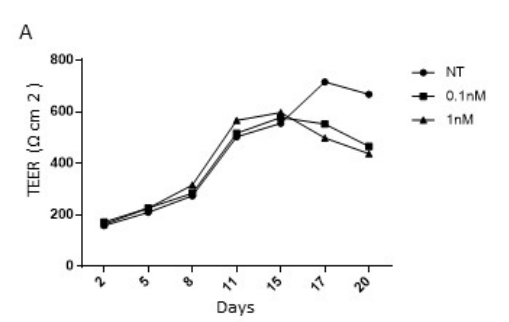

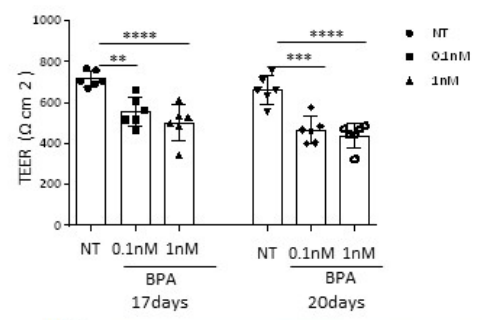

C

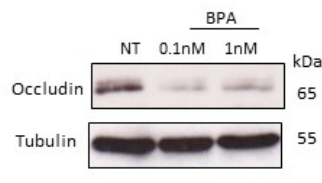

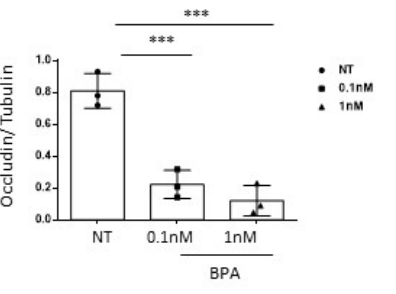

$\mathrm{E}$

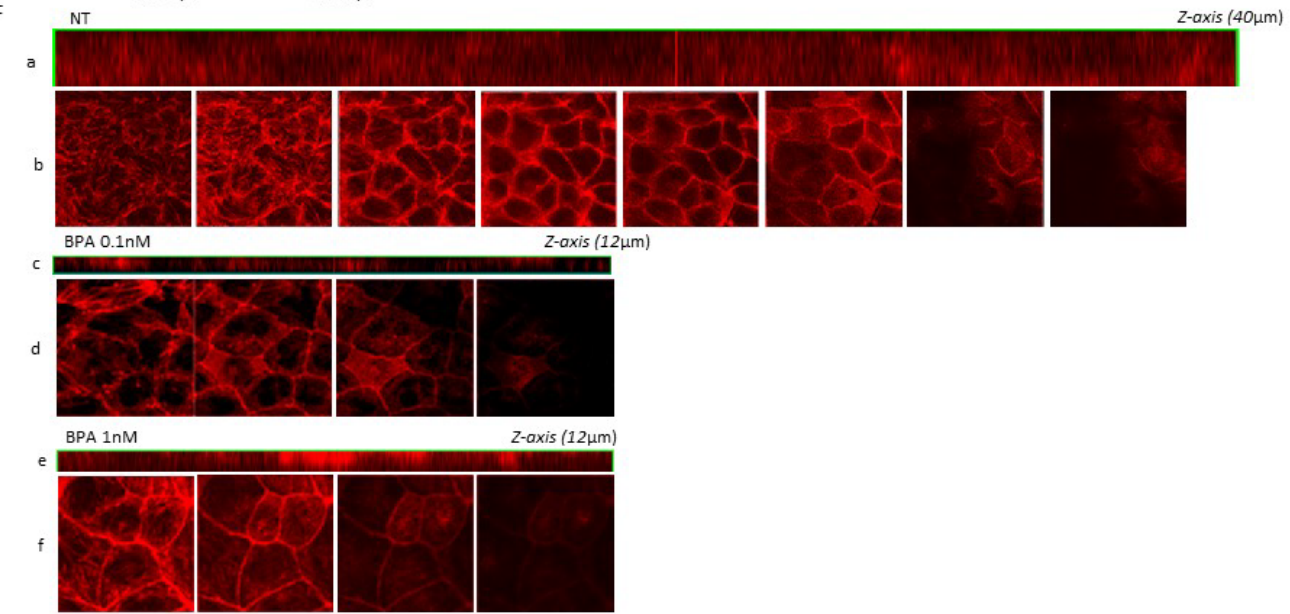

Figure 1. Effect of bisphenol-A (BPA) on intestinal permeability. (A-B) Caco 2 cells were grown in monolayers and treated with 0.1 and $1 \mathrm{nM}$ BPA during differentiation (20 days). The time course in which BPA $(0.1$ and $1 \mathrm{nM})$ induced a decrease in TEER at 17 and 20 days compared to the TEER in control cells. Columns represent the means, and bars represent the standard deviations of three independent experiments. ANOVA with Bonferroni correction was performed to compare BPA-treated cells and non-treated cells $(\mathrm{NT})$. $\left(* * \mathrm{p}<0.01,{ }^{*} * * * \mathrm{p}<0.0001\right)$. $(\mathrm{C}-$ D) Protein lysates from untreated Caco 2 cells and Caco2 cells treated with BPA at different concentrations $(0.1 \mathrm{nM}$ and $1 \mathrm{nM})$ were analysed by Western blot analysis using antibodies for occludin and tubulin, which was used as a loading control. The autoradiographs shown are representative of three independent experiments and were subjected to densitometric analysis. Asterisks denote statistically significant differences $(* * * \mathrm{p}<0.001)$. (E) Caco2 monolayers were treated with 0.1 and $1 \mathrm{nM}$ BPA and stained with anti-occludin antibody before observation by confocal microscopy. (F) Confocal fluorescence localization of actin along the $z$-axis. The results are representative of three separate experiments showing similar results

A

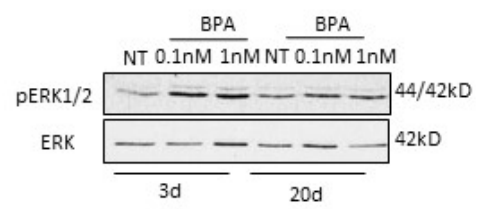

B

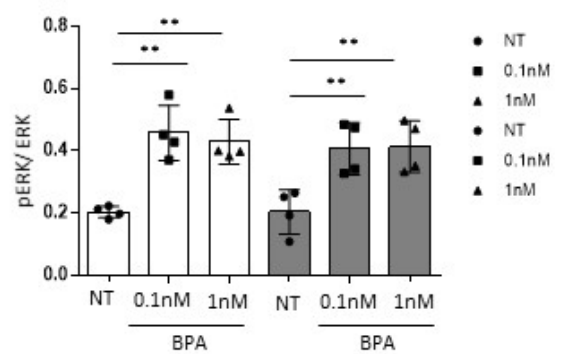

$\mathrm{C}$

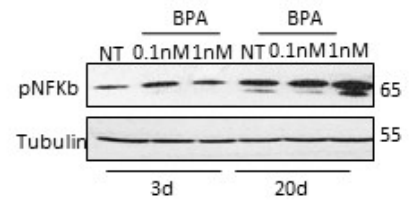

D

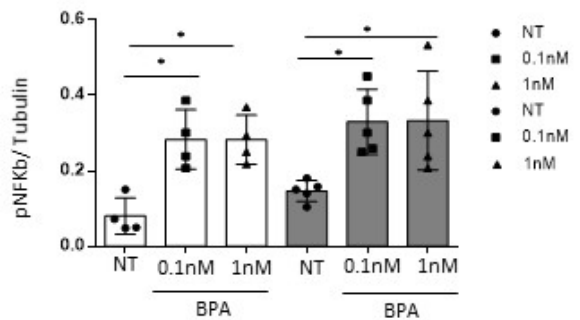

E

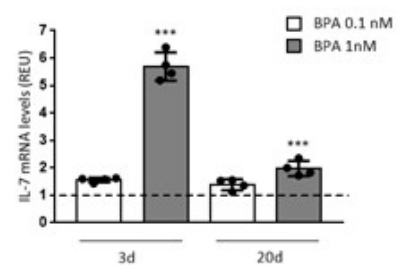

$\mathrm{F}$

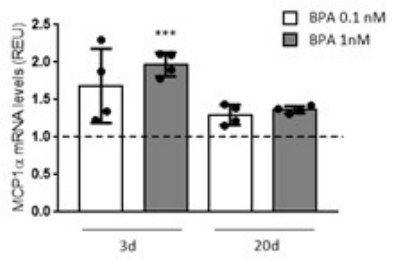

Figure 2. BPA activates inflammatory pathways. Protein lysates from untreated Caco2 cells and Caco2 cells treated with different concentrations of BPA ( 0.1 and 1 nM) for 30 minutes during differentiation (3-20 days) were analysed by Western blot analysis using antibodies for p-ERK1/2, ERK (A-B) and pNF-kB (C-D). Tubulin was used as a loading control. The autoradiographs are representative of four independent experiments and were subjected to densitometric analysis. ANOVA with Bonferroni correction was performed to compare BPAtreated cells and non-treated cells (NT). Asterisks denote statistically significant differences $\left({ }^{*} \mathrm{p}<0.05,{ }^{*} \mathrm{p}<0.01\right)$. (E-F) IL-7 and MCP1 mRNA levels in Caco 2 cells during differentiation after 3 and 20 days of $0.1 \mathrm{nM}$ and $1 \mathrm{nM}$ BPA incubation were assayed by real-time RT-PCR analysis; the results are expressed as the relative expression units (REU). PPIA was used as a standard control. Bars represent the mean \pm SD of three independent experiments. ANOVA with Bonferroni correction was performed to compare BPA-treated cells and non-treated cells (NT). Asterisks indicate statistically significant differences $(* * * p<0.001)$ 

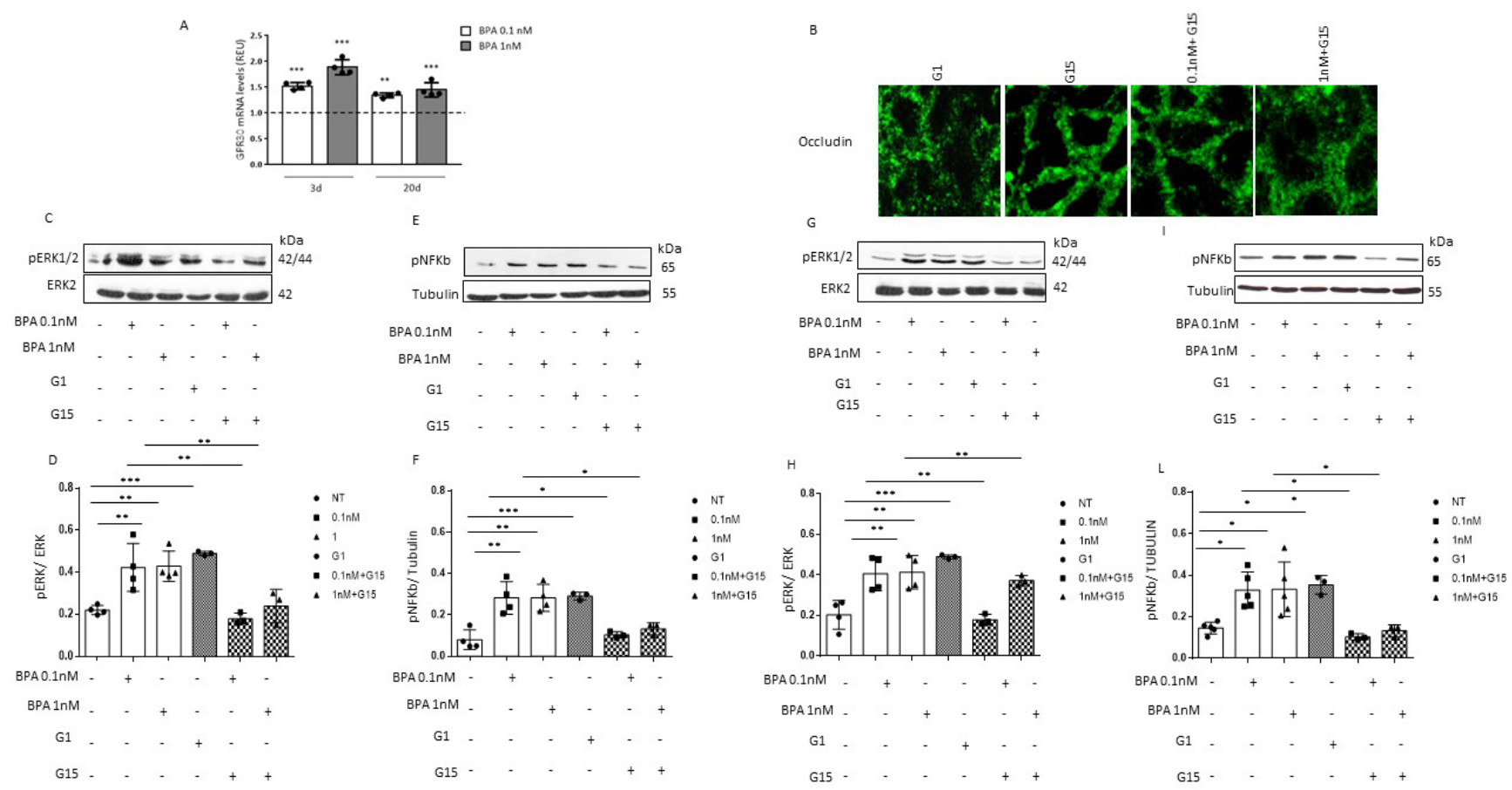

Figure 3. BPA increases GPR 30 expression and function. (A) GPR30 mRNA levels in Caco 2 cells during differentiation after 3 and 20 days of $0.1 \mathrm{nM}$ and $1 \mathrm{nM}$ BPA incubation were assayed by RT real-time PCR analysis and are expressed as relative expression units (REU). Bars represent the mean \pm SD of three independent experiments. ANOVA with Bonferroni correction was performed to compare BPA-treated cells and non-treated cells (NT). Asterisks indicate statistically significant differences $(* * p<0.01 ; * * * p<0.001)$. (B) Caco 2 monolayers were treated with different concentrations of BPA $(0.1$ and $1 \mathrm{nM})$ and treated with G-1 $(100 \mathrm{nM})$ and G15 $(1 \mu \mathrm{M})$. Then, the cells were stained with anti-occludin antibody. Confocal microscopy revealed the disruption of tight junctions upon G-1 treatment, as was observed following BPA exposure, while G15 treatment prevented the deleterious effect of BPA. Protein lysates from untreated Caco2 cells and Caco2 cells treated with BPA at different concentrations ( $0.1 \mathrm{nM}$ and $1 \mathrm{nM}), \mathrm{G}-1$ (100 nM) or G15 (1 $\mu \mathrm{M})$ were analysed by Western blot analysis using antibodies for pERK1/2, pNF-кB, ERK1/2 and tubulin, which was used as a loading control, after 3 days (C-F) and 20 days (G-L) of differentiation. The autoradiographs are representative of four independent experiments. ANOVA with Bonferroni correction was performed to compare BPA-treated cells and non-treated cells (NT). Asterisks denote statistically significant differences $(* \mathrm{p}<0.05 ; * * \mathrm{p}<0.01 ; * * * \mathrm{p}<0.001)$

Table 2. Caco2 released cytokines and growth factors

\begin{tabular}{|c|c|c|c|}
\hline Cytokine/growth factor $(\mathrm{pg} / \mathrm{mL})$ & CTRL & BPA $(0.1 \mathrm{nM})$ & BPA (1 nM) \\
\hline IL- $1 \beta$ & $3,095 \pm 0,386$ & $2,963 \pm 0,213$ & $2,79 \pm 0,542$ \\
\hline IL-1ra & $102,396 \pm 2,375$ & $95,143 * * \pm 3,414$ & $91,357 * * \pm 3,285$ \\
\hline IL-2 & $18,573 \pm 0,878$ & $18,47 \pm 0,966$ & $18,07 \pm 0,565$ \\
\hline IL-4 & $2,366 \pm 0,159$ & $2,276 \pm 0,192$ & $2,183 \pm 0,060$ \\
\hline IL-5 & $5,815 \pm 0,179$ & $5,855 \pm 0,148$ & $6,502 * \pm 0,454$ \\
\hline IL-6 & $10,49 \pm 0,382$ & $10,03 \pm 0,471$ & $10,15 \pm 0,359$ \\
\hline IL-7 & $3,144 \pm 0,193$ & $4,16^{*} \pm 0,240$ & $4,106^{*} \pm 0,526$ \\
\hline IL-8 & $29,406 \pm 9,948$ & $21,526 \pm 9,7062$ & $24,386 \pm 6,16903$ \\
\hline IL-9 & $15,863 \pm 0,206$ & $14,68 \pm 0,866$ & $14,427 \pm 0,849$ \\
\hline IL-10 & $81,383 \pm 7,361$ & $86,983 \pm 13,234$ & $80,04 \pm 2,616$ \\
\hline IL-12 & $386,653 \pm 23,208$ & $397,505 \pm 75,682$ & $357,052 \pm 41,264$ \\
\hline IL-13 & $18,39 \pm 1,390$ & $16,405 \pm 2,088$ & $18,467 \pm 2,162$ \\
\hline IL-15 & $20,083 \pm 0,848$ & $18,853 \pm 1,212$ & $19,202 \pm 1,851$ \\
\hline IL-17 & $27,793 \pm 0,416$ & $26,86 \pm 1,509$ & $27,326 \pm 1,006$ \\
\hline Eotaxin & $23,163 \pm 0,550$ & $22,123 \pm 2,161$ & $23,713 \pm 0,545$ \\
\hline bFGF & $43,466 \pm 3,371$ & $48,253 \pm 6,398$ & $45,056 \pm 3,043$ \\
\hline G-CSF & $29,36 \pm 0,946$ & $28,316 \pm 2,188$ & $29,69 \pm 2,325$ \\
\hline GM-CSF & $55,816 \pm 0,963$ & $52,263 \pm 4,329$ & $48,59 \pm 3,034$ \\
\hline IFN $\gamma$ & $79,753 \pm 5,965$ & $74,043 \pm 5,368$ & $74,52 \pm 1,992$ \\
\hline IP-10 & $222,41 \pm 19,990$ & $230,343 \pm 50,996$ & $213,11 \pm 42,083$ \\
\hline MIP-1a & $1,093 \pm 0,068$ & $1,085 \pm 0,054$ & $1,197 \pm 0,185$ \\
\hline MIP-1b & $8,583 \pm 0,248$ & $8,603 \pm 0,651$ & $7,786 \pm 0,529$ \\
\hline MCP1 & $9,51 \pm 0,098$ & $10,76^{*} \pm 0,076$ & $11,005^{* *} \pm 0,404$ \\
\hline PDGF & $90,25 \pm 2,871$ & $85,865 \pm 2,722$ & $99,625 * \pm 0,756$ \\
\hline Rantes & $26,9 \pm 0,537$ & $26,615 \pm 1,427$ & $26,64 \pm 0,547$ \\
\hline $\mathrm{TNF} \alpha$ & $25,89 \pm 0,514$ & $25,67 \pm 1,160$ & $28,566 \pm 5,696$ \\
\hline VEGF & $2738,802 \pm 425,326$ & $2586,653 \pm 537,244$ & $2708,85 \pm 482,474$ \\
\hline
\end{tabular}

Miss some cytokine. A panel of 27 different cytokines, chemokines and growth factors produced by differentiated Caco 2 cells was assayed in untreated cells and cells treated with $0.1 \mathrm{nM}$ and $1 \mathrm{nM}$ BPA using the Bio-Plex multiplex cytokine assay kit, as described in the Methods section $\left({ }^{*} \mathrm{p}<0.05 ;{ }^{*} \mathrm{p}<0.01\right)$ 


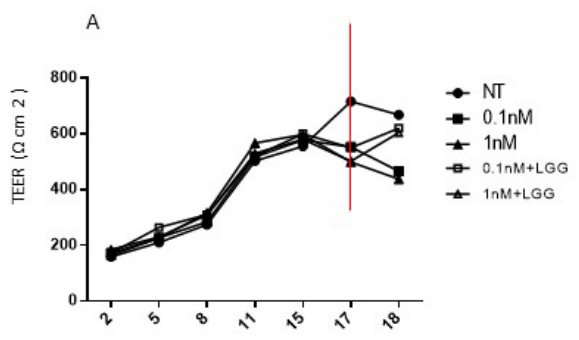

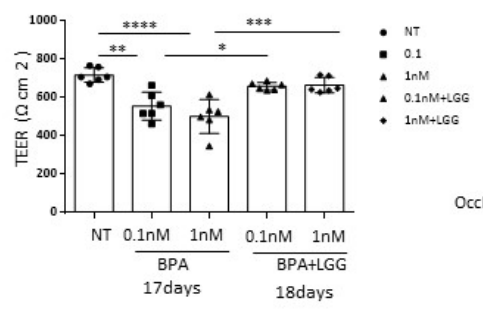

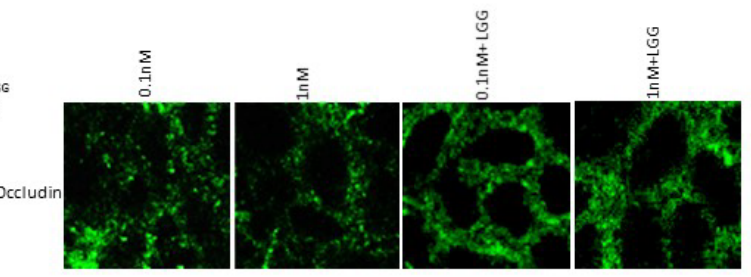

$$
\text { D }
$$

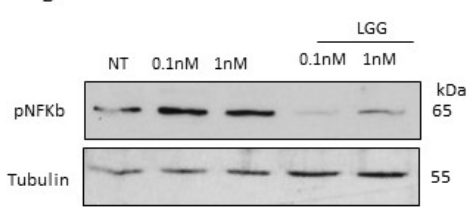

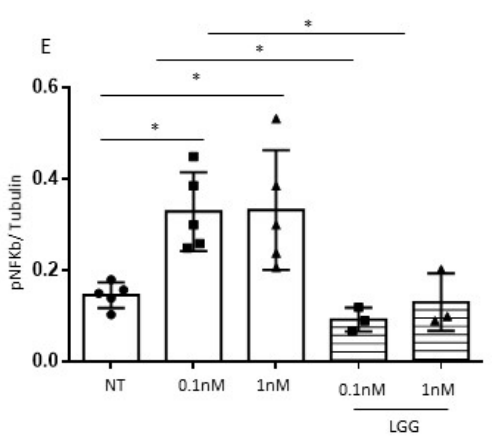

- NT

- $0.1 \mathrm{nM}$

- $1 \mathrm{nM}$

- $0.1 \mathrm{nM}+\mathrm{LGG}$

- $1 \mathrm{nM}+\mathrm{LGG}$

Figure 4. Effect of LGG supernatant on BPA. (A-B) Caco 2 cells were grown in monolayers and treated with 0.1 and $1 \mathrm{nM}$ BPA during differentiation. Time course of the 0.1 and $1 \mathrm{nM}$ BPA-induced decrease in TEER after 17 days of differentiation with respect to the control after treatment with LGG for 24 hours (red line). Columns represent the means, and bars represent the standard deviations of three independent experiments. A Bonferroni test was performed to compare BPA- and LGG-treated sample with the NT sample $\left({ }^{*} \mathrm{p}<0.05, * * \mathrm{p}<0.01, * * * \mathrm{p}<0.001\right.$, $* * * * \mathrm{p}<0.0001$ ). (D-E) Caco2 cells were treated for 30 minutes with LGG, stimulated with 0.1 and $1 \mathrm{nM} \mathrm{BPA}$ and analysed by Western blot analysis using antibodies for $\mathrm{pNF}-\mathrm{kB}$ and tubulin, which was used as a loading control. The autoradiographs shown are representative of three independent experiments and were subjected to densitometric analysis. ANOVA with Bonferroni correction was performed to compare BPA-treated cells with non-treated cells (NT) and cells after LGG treatment. Asterisks denote statistically significant differences $(* \mathrm{p}<0.05$ )

conditions, LGG supplementation inhibited the BPA-mediated decrease in TEER (Figures 4A and 4B). Moreover, LGG significantly increased the levels of occludin and prevented the activation of pNF$\kappa \mathrm{B}$ induced by BPA (Figures 4C-4E).

Taken together, our results indicated that LGG supernatant could limit the effects of BPA on intestinal barrier function.

\section{Discussion}

In this study, we have revealed that BPA at $0.1 \mathrm{nM}$ and $1 \mathrm{nM}$ significantly decreases TEER and deregulates TJ integrity, accompanied by decreased $\mathrm{Caco} 2$ monolayer thickness. Moreover, during cell differentiation, BPA enhances inflammatory pathways by increasing p65 expression, which an indicator of NF- $\mathrm{BB}$, and simultaneously stimulates the secretion of pro-inflammatory mediators, such as IL-7 and MCP1. The pro-inflammatory effects of BPA seem to be mediated by GPR30 overexpression and activation. Indeed, the same deleterious effects of BPA were produced in $\mathrm{Caco} 2$ cells treated with the selective GPR30 agonist G1 and reversed by G15, a specific GPR30 antagonist.

The inflammatory effects of BPA on undifferentiated Caco2 cells suggest that early BPA exposure, for example, that derived by maternal food and beverage ingestion, may disrupt normal pre- and post-natal maturation of the gut during its development, with possible permanent epigenetic and trans-generational modifications $[27,28,45]$

In addition, continuous BPA ingestion in adults might affect undifferentiated/stem cells residing at the bottom of the crypt villus, which are in contact with different intestinal intraepithelial lymphocytes and therefore have a strong influence on gut immune regulation $[34,46,47]$.

In particular, increased intestinal permeability is an early event in mucosal inflammation related to barrier dysfunction, and an increased risk of colorectal cancer is related to long-term chronic inflammation $[48,49]$. BPA in its active and free form, which is present in food and beverages, first and most frequently contacts the gut epithelium [19] and plays a relevant role in the predisposition of local and systemic inflammatory pathologies.

Growing evidence shows the endocrine-disrupting effects of BPA at doses lower than the reference limits [25-28,50]. In this manuscript, we used very low doses of BPA $(0.1$ and $1 \mathrm{nM})$ to test the inflammatory pathway by determining the levels of NF- $\kappa$ B.

$\mathrm{NF}-\kappa \mathrm{B}$ plays a central role in the regulation of chronic inflammation by controlling the transcription of inflammation genes, and NF- $\kappa \mathrm{B}$ dimers containing p65 appear to have profound pro-inflammatory activity [51].

In our experiments, NFkB levels were increased following the treatment of undifferentiated cells with BPA at both 0.1 and $1 \mathrm{nM}$ and after 20 days of differentiation. These results again indicate that less differentiated epithelial cells are sensitive to very small doses of BPA. These effects were followed by moderately increased secretion of the pro-inflammatory chemokines IL-7 and MCP-1 in the medium. IL7, a well-known pro-inflammatory cytokine produced by intestinal epithelial cells, mainly goblet cells, is a pleiotropic immune regulatory protein involved in the survival, proliferation, differentiation and maturation of B and T lymphocytes [52-55]. MCP-1 is a chemokine reported to be increased in IBD patients compared with normal healthy subjects that plays a prominent role in enhancing the severity of intestinal as well as systemic inflammation [56-58].

GPR30, a non-classical oestrogen receptor, is involved in modulating many biological processes, including immune responses and gastrointestinal physiology, influencing intestinal barrier maturation [25,59-61]. In particular, the presence of GPR30 in gut 
mucosa mast cells has been reported to be increased in IBD patients [62]. In line with the results of Chan published in 2010, we describe the increased expression and activity of GPR30 on Caco 2 cells incubated with BPA, supported by the activation of ERK1/2 [63].

Recently, it was demonstrated that BPA at $0.1 \mathrm{nM}$ induced inflammation in cultured mature mammary adipocytes and SVF cells isolated from human adipose tissue biopsies [25].

LGG and its supernatant (or post-biotic) can improve intestinal barrier function [64]. Post-biotics have most of the effects of the original bacteria but not all the problems related to bacterial therapy [40-42]. For this reason, we used LGG supernatant for our experiments. Interestingly, LGG supernatant prevented the effects of BPA on TEER, TJ distribution and inflammation.

Previous works have highlighted the role of probiotics in BPAinduced effects. Bifidobacterium breve strain Yakult and Lactobacillus casei strain Shirota could exert a protective effect against dietary exposure to BPA in rats [31], and interestingly, certain probiotics were found to have the capability to remove BPA from an aqueous solution [32]. We used post-biotic from LGG probiotic to demonstrate that most of the effects of BPA can be prevented in the absence of bacterial bodies. Recent studies have shown the beneficial effects of post-biotics in vivo and in vitro [40-42,65-67]. Whether BPA exposure contributes to an increased risk of developing intestinal inflammation that post-biotics can prevent remains to be better defined through in vivo or ex vivo studies.

\section{Acknowledgements}

None.

\section{Conflict of interest}

The authors declare that they have no conflicts of interest.

\section{Authors contribution}

$\mathrm{MN}$ and IC were the main contributors in terms of the design, acquisition, interpretation of data and drafting of the article. CC, VDE, FO, RT, PF contributed to the analysis, interpretation and discussion of the results. MVB and RV mainly contributed to the conceptual design, interpretation, discussion of the results and supervision of the overall work. All the authors critically revised and approved the final version.

\section{References}

1. Podolsky DK (2002) Inflammatory bowel disease. NEJM 347: 417-429.

2. Molodecky NA, Soon IS, Rabi DM, Ghali WA, Ferris M, et al (2012) Increasing incidence and prevalence of the inflammatory bowel diseases with time, based on systematic review. Gastroenterology 142: 46-54. [Crossref]

3. Abraham C, Cho JH (2009) Inflammatory bowel disease. NEJM 361: 2066-2078. [Crossref]

4. Hossain P, Kawar B, El Nahas M (2007) Obesity and diabetes in the developing world-a growing challenge. NEJM 356: 213-215.

5. Hursting SD, Dunlap SM (2012) Obesity, metabolic dysregulation, and cancer: a growing concern and an inflammatory (and microenvironmental) issue. Annals of the New York Academy of Sciences 1271: 82-87.

6. Khor B, Gardet A, Xavier RJ (2011) Genetics and pathogenesis of inflammatory bowel disease. Nature 474: 307-317.

7. Kaser A, Zeissig S, Blumberg RS (2010) Inflammatory bowel disease. Annu Rev Immunol 28: 573-621.

8. Baumgart DC, Carding SR (2007) Inflammatory bowel disease: cause and immunobiology. Lancet 369: 1627-1640.
9. Lubrano C, Genovesi G, Specchia P, Costantini D, Mariani S, et al. (2013) Obesity and metabolic comorbidities: environmental diseases? Oxid Med Cell Longev 2013: 640673 .

10. Ritchie SA, Connell JM (2007) The link between abdominal obesity, metabolic syndrome and cardiovascular disease. Nutr Metab Cardiovasc Dis 17: 319-326. 18

11. Savastano S, Tarantino G, D'Esposito V, Passaretti F, Cabaro S, et al. (2015) Bisphenol-A plasma levels are related to inflammatory markers, visceral obesity and insulin-resistance: a cross-sectional study on adult male population. Journal of Translational Medicine 13.

12. Rubin BS (2011) Bisphenol A: an endocrine disruptor with widespread exposure and multiple effects. J Steroid Biochem Mol Biol 127: 27-34.

13. Gregor MF, Hotamisligil GS (2011) Inflammatory mechanisms in obesity. Annu Rev Immunol 29: 415-445.

14. Rochester JR (2013) Bisphenol A and human health: a review of the literature. Reprod Toxicol 42: 132-155.

15. Valentino R, D'Esposito V, Passaretti F, Liotti A, Cabaro S, et al. (2013) Bisphenol-A impairs insulin action and up-regulates inflammatory pathways in human subcutaneous adipocytes and 3T3-L1 cells. PLoS One: e82099.

16. Ariemma F, D'Esposito V, Liguoro D, Oriente F, Cabaro S, et al. (2016) Low-Dose Bisphenol-A impairs adipogenesis and generates dysfunctional 3T3-L1 Adipocytes. PLoS One 11: e0150762.

17. Camarca A, Gianfrani C, Ariemma F, Cimmino I, Bruzzese D, et al. (2016) Human peripheral blood mononuclear cell function and dendritic cell differentiation are affected by Bisphenol-A Exposure. PLoS One 11: e0161122.

18. Braniste V, Jouault A, Gaultier E, Polizzi A, Buisson-Brenac C, et al. (2010) Impact of oral bisphenol A at reference doses on intestinal barrier function and sex differences after perinatal exposure in rats. Proceedings of the National Academy of Sciences of the United States of America 107: 448-453.

19. Vandenberg LN, Hauser R, Marcus M, Olea N, Welshons WV (2007) Human exposure to bisphenol A (BPA). Reprod Toxicol 24: 139-177.

20. Maloy KJ, Powrie F (2011) Intestinal homeostasis and its breakdown in inflammatory bowel disease. Nature 474: 298-306. [Crossref]

21. Prossnitz ER, Arterburn JB, Smith HO, Oprea TI, Sklar LA, et al. (2008) Estrogen signaling through the transmembrane G protein-coupled receptor GPR30. Annu Rev Physiol 70: 165-190.

22. Lee HR, Jeung EB, Cho MH, Kim TH, Leung PC, et al. (2013) Molecular mechanism(s) of endocrine-disrupting chemicals and their potent oestrogenicity in diverse cells and tissues that express oestrogen receptors. J Cell Mol Med 17: 1-11.

23. Sajiki J, Takahashi K, Yonekubo J (1999) Sensitive method for the determination of bisphenol-A in serum using two systems of high-performance liquid chromatography. $J$ Chromatogr B Biomed Sci Appl 736: 255-261.

24. Jalal N, Surendranath AR, Pathak JL, Yu S, Chung CY (2018) Bisphenol A (BPA) the mighty and the mutagenic. Toxicol Rep 5: 76-84. [Crossref]

25. Cimmino I, Oriente F, D'Esposito V, Liguoro D, Liguoro P, et al. (2019) Low dose Bisphenol-A regulates inflammatory cytokines through GPR30 in mammary adipose cells. J Mol Endocrinol 63: 273-283.

26. Huang D, Wu J, Su X, Yan H, Sun Z (2017) Effects of low dose of bisphenol A on the proliferation and mechanism of primary cultured prostate epithelial cells in rodents. Oncol Lett 14: 2635-2642.

27. Menard S, Guzylack-Piriou L, Leveque M, Braniste V, Lencina C, et al. (2014) Food intolerance at adulthood after perinatal exposure to the endocrine disruptor bisphenol A. FASEB journal 28: 4893-4900.

28. Feng L, Chen S, Zhang L, Qu W, Chen Z (2019) Bisphenol A increases intestinal permeability through disrupting intestinal barrier function in mice. Environ Pollut 254 : 112960.

29. Vieira AT, Teixeira MM, Martins FS (2013) The role of probiotics and prebiotics in inducing gut immunity. Front Immunol 4: 445.

30. Capurso L (2019) Thirty years of lactobacillus rhamnosus GG: A review. J Clin Gastroenterol 1: 1-41.

31. Oishi K, Sato T, Yokoi W, Yoshida Y, Ito M, et al. (2008) Effect of probiotics, Bifidobacterium breve and Lactobacillus casei, on bisphenol A exposure in rats. Biosci Biotechnol Biochem 72: 1409-1415. 
32. Solouki S RFM, Solouki S (2018) Efficiency of multispecies probiotic supplements in bioremoval of Bisphenol A: An in vitro study. Applied Food Biotechnology 5: 37-45.

33. Hidalgo IJ, Raub TJ, Borchardt RT (1989) Characterization of the human colon carcinoma cell line (Caco2) as a model system for intestinal epithelial permeability. Gastroenterology 96: 736-749.

34. Raimondi F, Santoro P, Barone MV, Pappacoda S, Barretta ML, et al. (2008) Bile acids modulate tight junction structure and barrier function of $\mathrm{Caco} 2$ monolayers via EGFR activation. Am J Physiol Gastrointest Liver Physiol 294: G906-913.

35. Nanayakkara M, Kosova R, Lania G, Sarno M, Gaito A, et al. (2013) A celiac cellular phenotype, with altered LPP sub-cellular distribution, is inducible in controls by the toxic gliadin peptide P31-43. PLoS One 8: e79763.

36. Nanayakkara M, Lania G, Maglio M, Discepolo V, Sarno M, et al. (2013) An undigested gliadin peptide activates innate immunity and proliferative signaling in enterocytes: the role in celiac disease. The American Journal of Clinical Nutrition 98: 1123-1135.

37. Ricci S, Viggiano D, Cimmino I, Perruolo G, Cabaro S, et al. (2018) Prep1 deficiency affects olfactory perception and feeding behavior by impairing BDNF-TrkB mediated neurotrophic signaling. Mol Neurobiol 55: 6801-6815.

38. Cimmino I, Lorenzo V, Fiory F, Doti N, Ricci S, et al. (2017) A peptide antagonist of Prep1-p160 interaction improves ceramide-induced insulin resistance in skeletal muscle cells. Oncotarget 8: 71845-71858.

39. Liotti A, Cabaro S, Cimmino I, Ricci S, Procaccini C, et al. (2018) Prep1 deficiency improves metabolic response in white adipose tissue. Biochim Biophys Acta 1863: 515525 .

40. Sarno M, Lania G, Cuomo M, Nigro F, Passannanti F, et al. (2014) Lactobacillus paracasei CBA L74 interferes with gliadin peptides entrance in Caco2 cells. Int J Food Sci Nutr 65: 953-959.

41. Labruna G, Nanayakkara M, Pagliuca C, Nunziato M, Iaffaldano L, et al. (2019) Celiac disease-associated Neisseria flavescens decreases mitochondrial respiration in $\mathrm{Caco} 2$ epithelial cells: Impact of Lactobacillus paracasei CBA L74 on bacterial-induced cellular imbalance. Cell Microbiol 21: e13035.

42. Gallo M, Nigro F, Passannanti F, Nanayakkara M, Lania G, et al. (2019) Effect of pH control during rice fermentation in preventing a gliadin P31-43 entrance in epithelial cells. Int J Food Sci Nutr 70: 950-958.

43. Zhu J, Jiang L, Liu Y, Qian W, Liu J, et al. (2015) MAPK and NF-kappaB pathways are involved in bisphenol A-induced TNF-alpha and IL-6 production in BV2 microglial cells. Inflammation 38: 637-648.

44. Shi JH, Sun SC (2018) Tumor necrosis factor receptor-associated factor regulation of nuclear factor kappab and mitogen-activated protein kinase pathways. Front Immunol 9: 1849 .

45. Ponzi D GL, Parmigiani S, Palanza P (2020) Effects of prenatal exposure to a low-dose of bisphenol a on sex differences in emotional behavior and central alpha 2-adrenergic receptor binding. Int J Mol Sci 21.

46. Patterson TA, Brot MD, Zavosh A, Schenk JO, Szot P, et al. (1998) Food deprivation decreases mRNA and activity of the rat dopamine transporter. Neuroendocrinology 68 : $11-20$.

47. Nozaki K, Mochizuki W, Matsumoto Y, Matsumoto T, Fukuda M, et al. (2016) Coculture with intestinal epithelial organoids allows efficient expansion and motility analysis of intraepithelial lymphocytes. J Gastroenterol 51: 206-213.

48. Soderholm JD, Olaison G, Peterson KH, Franzen LE, Lindmark T, et al. (2002) Augmented increase in tight junction permeability by luminal stimuli in the noninflamed ileum of Crohn's disease. Gut 50: 307-313.

49. Rubin DC, Shaker A, Levin MS (2012) Chronic intestinal inflammation: inflammatory bowel disease and colitis-associated colon cancer. Front Immunol 3: 107.
50. vom Saal FS, Hughes C (2005) An extensive new literature concerning low-dose effects of bisphenol A shows the need for a new risk assessment. Environ Health Perspect 113: 926-933.

51. Schreiber S, Nikolaus S, Hampe J (1998) Activation of nuclear factor kappa B inflammatory bowel disease. Gut 42: 477-484.

52. Totsuka T, Kanai T, Nemoto Y, Makita S, Okamoto R, et al. (2007) IL-7 Is essentia for the development and the persistence of chronic colitis. J Immunol 178: 4737-4748.

53. Watanabe M, Ueno Y, Yajima T, Iwao Y, Tsuchiya M, et al. (1995) Interleukin 7 is produced by human intestinal epithelial cells and regulates the proliferation of intestinal mucosal lymphocytes. The Journal of Clinical Investigation 95: 2945-2953.

54. Madrigal-Estebas L, McManus R, Byrne B, Lynch S, Doherty DG, et al. (1997) Human small intestinal epithelial cells secrete interleukin-7 and differentially express two different interleukin-7 mRNA Transcripts: implications for extrathymic T-cell differentiation. Hum Immunol 58: 83-90.

55. Bikker A, Hack CE, Lafeber FP, van Roon JA (2012) Interleukin-7: a key mediator in $\mathrm{T}$ cell-driven autoimmunity, inflammation, and tissue destruction. Curr Pharm Des 18 2347-2356.

56. Grimm MC, Elsbury SK, Pavli P, Doe WF (1996) Enhanced expression and production of monocyte chemoattractant protein-1 in inflammatory bowel disease mucosa. $J$ Leukoc Biol 59: 804-812.

57. Reinecker HC, Loh EY, Ringler DJ, Mehta A, Rombeau JL, et al. (1995) Monocytechemoattractant protein 1 gene expression in intestinal epithelial cells and inflammatory bowel disease mucosa. Gastroenterology 108: 40-50.

58. Singh UP, Singh NP, Murphy EA, Price RL, Fayad R, et al. (2016) Chemokine and cytokine levels in inflammatory bowel disease patients. Cytokine 77: 44-49.

59. Bolli A, Bulzomi P, Galluzzo P, Acconcia F, Marino M (2010) Bisphenol A impairs estradiol-induced protective effects against DLD-1 colon cancer cell growth. IUBMB Life 62: 684-687.

60. Dahlman-Wright K, Cavailles V, Fuqua SA, Jordan VC, Katzenellenbogen JA, et al (2006) International Union of Pharmacology. LXIV. Estrogen receptors. Pharmacol Rev 58: 773-781.

61. Looijer-van Langen M, Hotte N, Dieleman LA, Albert E, Mulder C, et al. (2011) Estrogen receptor-beta signaling modulates epithelial barrier function. Am J Physiol Gastrointest Liver Physiol 300: 621-626.

62. Qin B, Dong L, Guo X, Jiang J, He Y, et al. (2014) Expression of G protein-coupled estrogen receptor in irritable bowel syndrome and its clinical significance. Int J Clin Exp Pathol 7: 2238-2246.

63. Chan QK, Lam HM, Ng CF, Lee AY, Chan ES, et al (2010) Activation of GPR30 inhibits the growth of prostate cancer cells through sustained activation of Erk1/2, $\mathrm{c}$-jun/c-fos-dependent upregulation of $\mathrm{p} 21$, and induction of $\mathrm{G}(2)$ cell-cycle arrest. Cell Death Differ 17: 1511-1523.

64. Liu Q, Liu Y, Li F, Gu Z, Liu M, et al. (2020) Probiotic culture supernatant improves metabolic function through FGF21-adiponectin pathway in mice. J Nutr Biochem 75: 108256.

65. Tsilingiri K, Barbosa T, Penna G, Caprioli F, Sonzogni A, et al. (2012) Probiotic and postbiotic activity in health and disease: comparison on a novel polarised ex-vivo organ culture model. Gut 61: 1007-1015.

66. Zagato E, Mileti E, Massimiliano L, Fasano F, Budelli A, et al. (2014) Lactobacillus paracasei CBA L74 metabolic products and fermented milk for infant formula have anti-inflammatory activity on dendritic cells in vitro and protective effects against colitis and an enteric pathogen in vivo. PLoS One 9: e87615.

67. Nocerino R, Di Costanzo M, Bedogni G, Cosenza L, Maddalena Y, et al. (2019) Dietary treatment with extensively hydrolyzed casein formula containing the probiotic lactobacillus rhamnosus GG prevents the occurrence of functional gastrointestinal disorders in children with cow's milk allergy. J Pediatr 213: 137-142. [Crossref]

Copyright: (C2020 Nanayakkara M. This is an open-access article distributed under the terms of the Creative Commons Attribution License, which permits unrestricted use, distribution, and reproduction in any medium, provided the original author and source are credited. 